\title{
Beyond markets, hierarchies, and hybrids: an institutional perspective on IT-enabled two-sided markets
}

\author{
Kai Reimers ${ }^{1}\left(\mathbb{D} \cdot\right.$ Xunhua Guo $^{2} \cdot$ Mingzhi Li $^{2}$ \\ Received: 15 October 2017 / Accepted: 19 October 2018 / Published online: 21 November 2018 \\ (C) The Author(s) 2018
}

\begin{abstract}
The term 'two-sided market', coined in the early 2000s, refers to a novel IT-enabled form of organizing economic activities exemplified by such firms as Uber, Amazon, and Taobao. While a rich literature has explored the phenomenon of two-sided markets, it has done so from a narrow technical perspective focusing on pricing issues. In this paper, we develop a novel framework to classify and characterize two-sided markets from an institutional perspective by extending and combining crucial categorical distinctions made by Williamson and Commons, one of the main sources of inspiration for Williamson's Transaction Cost Economics. This new classification scheme identifies three institutionally distinct types of two-sided markets which are functional equivalents of traditional forms described by Williamson as markets, hybrids, and hierarchies. This suggests that twosided markets may, under certain conditions, replace such traditional forms. We also develop a new proposition concerning the role of information technology in such a possible shift.
\end{abstract}

Keywords Two-sided markets $\cdot$ Institutional economics $\cdot$ Platform competition $\cdot$ IT-enabled organizational change $\cdot$ Coordination mechanisms

JEL classification $\mathrm{B} 52 \cdot \mathrm{L} 14 \cdot \mathrm{O} 33$

\section{Introduction}

With the penetration of the Internet new forms of economic organization have evolved that do not easily fit into traditional categories such as firms and markets. For example, online platforms such as Amazon, Taobao, and Uber can be viewed as firms whose product is the organization of a market. From a

Responsible Editor: Kai Riemer

Kai Reimers

reimers@wi.rwth-aachen.de

Xunhua Guo

guoxh@sem.tsinghua.edu.cn

Mingzhi Li

limzh@sem.tsinghua.edu.cn

1 Research Group Electronic Business, RWTH Aachen University, Johanniterstrasse 22-24, 52064 Aachen, Germany

2 Research Center for Contemporary Management, School of Economics and Management, Tsinghua University, Beijing 100084, China neoclassical economic perspective, such platforms are conceptualized as 'two-sided markets' (Rochet and Tirole 2006) or 'two-sided networks' (Parker and Alstyne 2005). The phenomenon has implications in several fields such as economics and organization theory; it is also clearly relevant for the IS field. However, to better address IS-relevant questions, such as what role IT plays in enabling and shaping two-sided markets, one needs to explain the phenomenon rather than just define it. Institutional Economics, specifically Williamson's Transaction Cost Economics, has proved to be very useful for understanding IT-relevant aspects of organizations, e.g. with regard to possible IT-induced shifts between forms of economic organization (Malone et al. 1987). We therefore in this paper ask: How to conceptualize the phenomenon of twosided markets from an institutional perspective?

We find that two-sided markets can be characterized as governance structures in their own right, similar to those described by Williamson (markets, hierarchies, and hybrids). Moreover, we identify three distinct kinds of two-sided markets that turn out to be functional equivalents to the governance structures described by Williamson. This suggests that the emergence of two-sided markets may herald a large-scale shift in economic organization from the traditional forms 
described by Williamson towards various new forms that are currently known as two-sided markets.

The possibility of such a large-scale shift in economic organization is reminiscent of the transformation of economic organization which took place in the nineteenth century when the giant, vertically integrated industrial firm pushed aside the long dominant forms of merchant-run markets and familyowned businesses, as famously described by Alfred Chandler (1980). He has attributed this shift to the rise of two technologies, the railroad and the telegraph. This suggests that we are presently in the midst of a similar large-scale shift of economic organization, this time driven by information technology. Building on the answer to our research question - How to conceptualize the phenomenon of two-sided markets from an institutional perspective? - we will also develop some first ideas for a hypothesis that could explain the role of IT in such a possible shift towards two-sided markets as new forms of economic organization.

Williamson has adapted older institutional thinking, including that of John R. Commons, to a specific problem, namely the 'make or buy decision', where 'make' refers to hierarchical and 'buy' to market-based forms of coordinating economic activities (Williamson 1975 and 1987). Consequently, the scope of his analysis, which is generally referred to as Transaction Cost Economics (TCE), is limited to institutional forms that can be mapped onto a continuum with markets and hierarchies at its end points (Hodgson 2002). Two-sided markets cannot be mapped onto this continuum since this continuum implies that as one moves towards the market pole one also moves away from the hierarchy pole. However, two-sided markets seem to have strong elements of both markets and hierarchies. In spite of these limitations, Williamson's overall methodological approach of comparing distinct structural alternatives from an institutional perspective holds great promise for the analysis of two-sided markets since it is likely that these phenomena, understood as governance structures, have emerged due to some comparative advantage related to their particular and novel institutional set-up, possibly enabled by information technology. We therefore propose to extend TCE in a way that allows for distinguishing between forms of economic organization without having to locate such forms on a continuum with markets and hierarchies at its end poles. To this end, we revisit the sources from which Williamson has drawn his inspiration, and here especially Commons whom Williamson has characterized as particularly influential for his thinking (Williamson 1987, $\mathrm{p}$. 3 ; 1996, pp. 220-221). The reason for this choice is that Commons' approach is the most comprehensive among the various proposals made by institutional economists, and hence also very complex and hard to encapsulate in a few theorems (Van de Ven 1993; Kaufman 2003 and 2007). It is therefore likely that in appropriating Commons' ideas Williamson deemphasized some ideas and concepts which, while not crucial to the questions he has addressed, mainly the make-or-buy decision, may be useful for understanding the new phenomenon of two-sided markets. Specifically, two-sided markets seem to have the potential to re-organize whole industries. Thus, seeking analytical help from a more comprehensive framework seems to be a promising undertaking.

We begin by examining the relevant literature on two-sided markets to demonstrate that, indeed, the phenomenon of twosided markets has not yet been evaluated from an institutional perspective. Next, we inspect both Commons' and Williamson's categorical distinctions, using each framework as a theoretical lens to identify the 'blind spots' in the other. Based on this juxtaposition of the two systems of categorical distinctions we then slightly extend each framework to account for these blinds spots so that the two frameworks can be combined to yield a more comprehensive classification system of institutional forms of organizing economic activities. We then use our new classification scheme to identify and characterize three distinct types of two-sided markets as functional equivalents of the three forms described by Williamson (markets, hybrids, and hierarchies), thus answering our research question. We finally develop a new proposition concerning the role of IT in possible shifts from Williamson's three forms to the three types of two-sided markets that we have identified.

\section{The focus of the literature on two-sided markets}

Originating in the early literature on network effects in the context of information technology standardization (Katz and Shapiro 1985; Farrell and Saloner 1985), the concept of twosided markets (Rochet and Tirole 2006) or two-sided networks (Parker and Alystine 2005) can be traced to pioneering works by Rochet and Tirole (2001) and Parker and Alystine (2000). Their intuition was that, for the case of so-called indirect network effects, there must be two or more 'user groups' which provide each other with network benefits. For example, users of software to create PDF documents depend upon users who use software that can read PDF documents. The more users there are that own software capable of reading PDF documents, the more worthwhile it becomes to own software that can create PDF documents and vice versa. In addition, often a third party is involved that brings these two user groups together, in this case this was, of course, the company Adobe which developed the PDF format and was an early producer of both types of software, PDF writing and PDF reading products. Accordingly, two-sided markets (or networks) are defined as consisting of two user groups that provide each other with network benefits and which are brought into contact with each other through a third party (Gallaugher and Wang 2002).

The early Adobe example also illustrates the main topic that the literature has explored subsequently, namely the question whether, and if so how, the platform provider should 
charge differential access and usage fees to participating user groups. As is commonly known, Adobe chose to provide its PDF reading software for free while charging relatively high prices for its PDF writing software, a choice which turned out to be very effective for Adobe. In their foundational paper, Rochet and Tirole (2001) have already mentioned a number of further applications of the basic idea such as operating systems as platforms (with application software users and developers as user groups), computer games (ditto), and media streaming networks (with content providers and consumers as user groups). Early formal applications referred to credit card systems as platforms (Rochet and Tirole 2002) and web server and web client (browser) software (equivalent to the Adobe case) (Gallaugher and Wang 2002).

The topic of platform access and usage pricing became so dominant in the literature that Rochet and Tirole (2006) have proposed to adopt a narrower technical definition of the concept of two-sided markets. Specifically, they suggest that only those markets should count as two-sided markets in which the choices of the platform provider regarding charging differential access and usage prices to the involved user groups affects economic outputs such as transaction volumes. If such choices do not affect economic outcome variables, for example because users can reverse such choices through bilateral negotiation, then a "one-sided" market exists and it would be a "waste of time" for public and private decision makers to concern themselves with matters of platform access and usage pricing (Rochet and Tirole 2006, p. 648).

In their "progress report" on the literature on two-sided markets, Rochet and Tirole (2006) also come closest to addressing issues relevant to institutional economists when they discuss the question whether traditional firms can also be viewed as instances of two-sided markets, thus potentially collapsing the distinction between hierarchical firms and markets. However, they conclude that such an application, while possible in principle, is unlikely to provide an accurate description of firms since, at least in competitive labor and product markets, firms have little "wriggle room" to adjust access and use fees (wages and product prices) to and of the firm viewed as a platform. Yet, far from moving towards studying institutional aspects of twosided markets, this idea rather shows that the concept is increasingly turned into a generic tool with which a broad variety of phenomena can be analyzed. By contrast, we want to retrieve an understanding of two-sided markets as an economic phenomenon (rather than as an analytical tool) by applying an institutional lens to bring forth hidden and possibly interesting and relevant aspects which have not yet been discussed - nor observed - in the literature. For example, one of our results is that there is one kind of two-sided markets which can be viewed as a functional equivalent to hierarchical governance structures, similar to the proposition by Rochet and Tirole, but which is institutionally distinct from hierarchies, contrary to what Rochet and Tirole have proposed.

\section{A new classification scheme: extending and combining Commons' and Williamson's categorical distinctions}

In this section, we present a novel analytical framework to classify institutional forms of organizing economic activities which extends and combines the analyses by Commons and Williamson so that various kinds of two-sided markets are revealed as emergent functional alternatives to traditional forms of economic organization such as markets, hybrids, and hierarchies. This new classification scheme is developed by juxtaposing crucial distinctions made by these two scholars such that each set of distinctions functions as a theoretical lens through which 'blind spots' of the other set of distinctions are made visible. However, this juxtaposing not only throws into relief the areas left hidden by each framework but also brings to the fore the fundamental conceptual links between them which allows for a new way of combining them. We proceed by first summarizing the core elements of each framework to the extent that they are relevant for our purpose; next, we point out which aspect of organizational life is left unexplained by each framework when examined in the light of the other and how the two frameworks can be extended accordingly. We then show how the two extended systems of categorical distinctions can be combined in a way which is consistent with the fundamental assumptions shared by both Commons and Williamson and which provides a more general description of forms of organizing economic activities. This new classification scheme is then used to characterize and distinguish three different types of two-sided markets. Finally, we validate our characterization of two-sided markets by checking whether the basic argument of Transaction Cost Economics, as developed by Williamson with regard to the traditional forms of markets, hybrids, and hierarchies, also applies to these new forms.

\section{Commons: three types of transactions}

Commons builds his monumental but also hard to penetrate "Institutional Economics" on the hypothesis that classical and neo-classical economics have largely failed to account for the institutional nature of economic relationships. Specifically, classical economists have conceptualized economic relationships as relations between man and nature which appears either in the form of physical productive resources or in the form of physical consumable commodities. His main claim is that, while these relationships are obviously important, they are controlled by various forms of collective action, subsumed under the concepts of going concern and custom, which limit and, at the same time, liberate and extend individual action. An institution, therefore, is defined "... as collective action in control, liberation and expansion of individual action" (Commons 1931, p. 648). Going concerns are purposefully 
organized forms of collective action while custom refers to emergent forms of collective action. ${ }^{1}$

Institutions thus refer to economic relations among actors. Such relations are characterized simultaneously by conflict of interest, interdependence, and order. Conflict of interest refers to the "principle of scarcity" in the sense that actors compete for scarce resources; interdependence refers to the "principle of efficiency" in that actors depend on each other for the creation of resources, i.e. in joint production processes; and order refers to the "principle of futurity" in that actors engage in relationships with other actors in the expectation of orderly conduct of transactions in the future. Institutions thus concern relationships between humans characterized simultaneously by the principles of scarcity, efficiency, and futurity. There are many other forms of human relationships, of course, so that any analysis derived from Commons' definition of institutions must be limited to relationships involving these three principles.

Since Commons' point of departure is the relationship between human actors, defined through and limited by the three principles of scarcity, efficiency, and futurity, his basic unit of analysis concerns the relationship between humans, not individual actions directed towards non-human objects such as exploitable productive resources and pleasure-giving commodities. Specifically, he defines as his basic unit of analysis a transaction which involves at least two human actors and distinguishes between three types of transactions, namely bargaining, rationing, and managerial transactions. A bargaining transaction describes the relationships between at least two prospective buyers and sellers respectively, who are all legal equals. A rationing transaction describes the relationship between a collective body as the superior and its members as inferiors where the collective body apportions benefits and burdens associated with the production of a collective good among its members. Finally, a managerial transaction describes the relationship between a superior, the manager, and her subordinates. Thus, in contrast to a rationing transaction, authoritative relations in a managerial transaction concern individuals, not groups. The purpose of a managerial transaction is the creation of resources whereas the purpose of a bargaining transaction is the sharing of resources. Commons is less explicit about the purpose of a rationing transaction; it appears that rationing transactions are related

\footnotetext{
${ }^{1}$ In this paper, we draw mostly on Commons' book "Institutional Economics" (1990, first published in 1934) but occasionally also refer to an earlier short article by Commons (1931) which outlines his main ideas. While the short article is a useful guide to and summary of chapter II of the book, which sets out his main ideas and concepts, an intensive reading of chapter II of the book is still necessary to reveal their internal connections and true meaning. As shown in the introduction by Malcolm Rutherford to the reissue of Commons' book (1990) as well as by more recent efforts by Kaufman (2003 and 2007) to introduce the partly opaque work of Commons to a contemporary audience, there are a number of inconsistencies in Commons' use of some of his concepts which makes reliance on a summarized version problematic. Unless otherwise indicated, we therefore refer to Commons' book in our presentation of his main ideas.
}

to both the creation and the sharing of resources, a fact which will become important in the development of our classification scheme. Typical examples for each type of transaction are: a two-sided auction on a stock exchange (bargaining transaction), the allocation of a budget in a multi-divisional firm (rationing transaction), and production planning and control in a firm (managerial transaction).

Without elaborating this idea, Commons proposes that these three types of transactions can be combined to form more complex forms of purposeful collective action, i.e. going concerns: "... there may be all degrees of combinations, for the three kinds of transactions are interdependent and variable in a world of collective action and perpetual change ..." (Commons 1990, p. 93). Thus, Commons views going concerns as potentially complex forms of collective action that combine two or all three types of transactions in various ways. Table 1 gives a high-level summary of Commons' theoretical framework.

\section{Williamson: three types of governance structures}

Williamson's point of departure is the claim that economics has traditionally concerned itself mostly with questions of allocative efficiency to the neglect of what he calls "first-order economizing" (Williamson 1996, p. 100). ${ }^{2}$ First-order economizing refers to effective adaptation and the elimination of waste (ibid.), i.e. to the ability of actors to adapt to often unanticipated changes of circumstance in market environments and a recognition of the importance of the costs of bureaucratization. The problem of allocative efficiency is understood as derivative - a second-order kind of economizing because the problems of effective adaptation and elimination of waste are considered to be of primary importance.

Williamson distinguishes between two kinds of adaptation which he calls type A, for "autonomous adaptation", and type C, for "cooperative adaptation". Autonomous adaptation occurs in well-functioning markets, i.e. in markets in which changes in supply and demand are sufficiently reflected in prices so that economic actors only have to respond to "parametric price changes" (Williamson 1996, p. 102) by adjusting their production and consumption plans accordingly. By contrast, autonomous adaptation will be ineffective when a long-term mutual

\footnotetext{
${ }^{2}$ We here mostly rely on a collection of articles published under the title "The Mechanisms of Governance" (1996); this book compiles articles that have appeared between 1983 and 1995 and thus have mostly followed on his second major book, "The Institutions of Capitalism", which was first published in 1985 and which itself was based on previously published articles. The 1985 book reflects the fact that Williamson has made allowance for a "hybrid" form of governance in response to wide-spread criticism of his initial dichotomy between "Markets and Hierarchies", the title of his first book which was published in 1975. We find the presentation of Transaction Cost Economics as outlined in the 1996 book more accessible than in the 1985 compilation but recognize the highly scattered nature of the presentation of his ideas as a possible source of misunderstandings and uneven appropriation of Williamson's ideas in the literature in general and the IS literature in particular (cf. Lacity and Khan 2016; Lee 2016).
} 
dependency enters into business relations. Self-interested bargaining will then lead to maladaptation in case of unanticipated changes in the environment because one or the other party can exploit the dependency-relation opportunistically. Hence, cooperative forms of adaptation are required, of which Williamson distinguishes two, namely hierarchies and hybrids.

Together with autonomous adaptation, which occurs in a 'pure' market setting, Williamson thus derives three "governance structures" which he characterizes as "syndromes of attributes", namely (1) incentive intensity, (2) extent of administrative controls, (3) performance attributes in terms of adaptation of type A and C, and (4) underlying contract law. Market governance is characterized by a high degree of incentive intensity, absence of administrative controls, and as especially good at autonomous adaptation while it scores last in terms of cooperative adaptation. The opposite holds true for hierarchies while hybrids score intermediate values for all these attributes. Williamson also claims that all three types have a distinct legal identity because three different "types of contract law", or rather three different legal doctrines, underlie them, namely a legalistic interpretation of contracts for the case of market governance, a doctrine of excuse for the case of hybrids where courts are more willing to interpret a contract in view of its spirit rather than according to its letter, and finally the doctrine of forbearance where courts refuse to address matters of internal conflict over resource allocation altogether so that hierarchies, i.e. firms, are constituted as their own system of last resort in cases of such conflicts.

Mutual dependence, as the root cause that necessitates cooperative forms of adaptation, is mostly created through socalled asset specificity, i.e. investments in assets the value of which correlates with the identity of business partners. For example, a supplier may invest in machine tools such as dies in order to efficiently supply metal components to a car manufacturer; however, should the customer decide to sever the relationship, these tools can only be converted to other purposes - such as supplying other car manufacturers with metal components - at a cost so that the value of such investments is tied to the business partners for whom they have been made. ${ }^{3}$

The choice between the three governance structures is then determined by the trade-offs established by the "syndrome of attributes" on the one hand and the extent of mutual dependence through asset specificity in business relationships on the other hand. High values of asset specificity call for more explicit forms of administrative controls, e.g. an arbitration regime, that sacrifice some degree of incentive intensity. In the extreme case, vertical integration results where a market

\footnotetext{
${ }^{3}$ Williamson also describes further factors contributing to the need for cooperative adaptation, namely uncertainty and transaction frequency (occasionally he also mentions difficulty of measurement as a fourth factor); however, these can only aggravate the problem of mutual dependency once some degree of asset specificity is established but do not, on their own, necessitate cooperative adaptation mechanisms, a fact which seems to have been overlooked in some parts of the IS literature that appropriates Transaction Cost Economics for the analysis of IT outsourcing decisions (Lacity and Khan 2016).
} 
Table 2 High-level summary of Williamson's theoretical framework

First-order economizing: elimination of waste (ability to adapt to unanticipated change; avoidance of bureaucratic cost) as opposed to second-order economizing (allocative, i.e. static efficiency); comprises two kinds of adaptation (autonomous and cooperative) which give rise to three kinds of governance structures (market, hierarchy, and hybrid)

Autonomous adaptation: no mutual dependency involved; response to parametric price changes sufficient $=>$ no additional (private) safeguarding of (market) transaction required

Market (reliance on public ordering): high incentive intensity, no administrative controls (bureaucracy); no asset specificity; legalistic doctrine
Cooperative adaptation: mutual dependency exists (mostly created through asset specificity); requires cooperative (privately regulated) forms of adaptation of which there are two kinds: hierarchy and hybrid

Hierarchy (unified ownership / vertical integration): low incentive intensity; extensive administrative controls (bureaucracy); high degree of asset specificity; doctrine of forbearance
Hybrid (institutional safeguarding of business relationship): intermediate values for incentive intensity, administrative controls, and asset specificity; doctrine of excuse relationship is replaced by a hierarchical arrangement. Hierarchies use "flat" incentives to stimulate cooperation and additional administrative controls to check for unwanted side effects which also means that incentive intensity is degraded and bureaucratic costs are increased. On the other hand, high degrees of asset specificity can offer efficiency advantages because more specialized machinery is deployed. Table 2 provides a high-level summary of Williamson's theoretical framework.

\section{Extending Commons' and Williamson's categorical distinctions}

It might be tempting to attempt to directly map Commons' three types of transactions onto Williamson's three types of governance structures by equating market governance with bargaining transactions, hierarchical governance with managerial transactions, and hybrid forms of governance with rationing transactions. However, whereas the first two pairs of categories, on first sight, allow for a plausible match, equating hybrids with rationing transactions would appear too restrictive; while some rationing may be involved in long-term cooperative arrangements, hybrids also rely on market contracting. Moreover, such a one-on-one mapping would also ignore Commons' proposition that going concerns, the equivalent of Williamson's governance structures, are often formed as combinations of two or even all three types of transactions. Thus, a simple one-on-one mapping of the two systems would suppress important aspects in each and, furthermore, fail to yield a more general framework that can be used to classify modern forms of economic organization such as two-sided markets. As a preparatory step for developing such a more general framework we therefore use each system to shed light on those aspects which are left hidden by the other system. Based on this analysis, we then slightly extend each system so as to make the two systems compatible with one another. This allows us to combine the two systems in a way which is theoretically justified and which leads to a more general description of forms of economic organization.

\section{Mutual adjustment transaction as a fourth transaction type}

Commons describes three types of transactions that all serve the purpose of coordinating some economic activities. By contrast, Williamson only distinguishes between two generic forms of coordination, namely autonomous and cooperative adaptation. Yet, the specific concern of Williamson, dedicated long-term institutional arrangements between actors entangled in a mutually dependent business relationship, points to a form of coordination which is not captured by Commons. Specifically, such arrangements do not rely on either bargaining, managerial, or rationing transactions but on some kind of coordinated interaction. Indeed, one of Williamson's main examples for illustrating hybrid governance structures is highly suggestive of the presence of a fourth coordination mechanism. Williamson quotes an excerpt from a contractual arrangement intended to regulate a supply relationship between two organizations over the unusual period of 32 years:

"“'In the event an inequitable condition occurs which adversely affects one Party, it shall then be the joint and equal responsibility of both Parties to act promptly and in good faith to determine the action required to cure or adjust for the inequity and effectively implement such action. ..."” (Williamson 1996, p. 96)

The coordination mechanism implied in this arrangement can neither be described as a bargaining, a managerial, or a rationing transaction. Instead, the contract appeals to the parties to mutual adjust each other's actions in case of unforeseen disturbances. Indeed, the idea of mutual adjustment as a distinct coordination mechanism is well established in organization theory (Mintzberg 1979). We therefore propose to extend Commons' framework by formally introducing a fourth type of transaction which we call a mutual adjustment transaction. This is defined as describing the relationship between two or more legal equals and as addressing the problem of combining resources in joint production processes. In a mutual adjustment transaction, the several parties continually observe each 
other's actions and, if necessary, adjust their actions to ensure that their actions, or rather their actions' output, fit together in view of some unanticipated environmental change. ${ }^{4}$ While both managerial and mutual adjustment transactions are aimed at the joint production of a resource, the nature of the involved parties differs. In a managerial transaction they are a superior and a subordinate, in a mutual adjustment transaction they are legal equals. It thus turns out that extending Commons' framework is quite straightforward since we can easily define this new form of transaction in terms of his own definitional terminology and arrive at a type of transaction that accurately characterizes important aspects of long-term supply relationships between firms as described by Williamson through his concept of hybrid governance. Table 3 shows and compares the four types of transactions that result from our extension.

\section{Private exchanges as a fourth type of governance structure}

Conversely, projecting Commons' analytical categories onto Williamson's distinction between three types of governance structures reveals a surprising gap in the latter: counter-intuitively, a bargaining transaction finds no place in Williamson's system of three primary governance structures. The obvious answer - to locate bargaining transactions in market governance - does not hold because Williamson describes market governance as consisting of autonomous adaptation to "parametric price changes", i.e. such price changes are assumed to be exogenous to the mechanism. The mechanism of autonomous adaptation itself consists of unilateral adjustments of production and consumption plans to such price changes. Williamson here incorporates the neoclassical ideal of perfectly competitive markets into his analytical apparatus, inclusive of its assumption of given prices. By contrast, Commons defines a bargaining transaction as involving at least four parties, two buyers and two sellers, who, in some kind of auction process, establish, i.e. generate a price. The coordinative function of a bargaining transaction thus consists in the fact that it generates prices which reflect the relative scarcity of supply in view of present demand and can therefore coordinate supply and demand. Thus, the coordination effect that Williamson ascribes to autonomous adaptation must, instead, be attributed to the prices to which actors respond which, in Williamson's analysis, are given

\footnotetext{
$\overline{4}$ Our definition of a 'mutual adjustment transaction' is consistent with the use of the term 'mutual adjustment' in organization theory, namely as referring to coordination actions among legal equals who need to ensure that their several activities fit together. However, in organization theory the term is usually used in a context of intra-organizational coordination whereas we want to use the term in a more general sense. This is indicated by our addition of the term 'transaction' which, in Commons' system who considers the 'transaction' to be the basic unit of analysis, allows for intra- as well as for inter-organizational application.
}

exogenously, i.e. the coordination effect through prices remains unexplained.

To amend this deficiency, one must bring the price mechanism as a coordination mechanism into the framework, and do so from an institutional perspective. Williamson is actually not completely blind in this regard, as he describes important institutional elements of market governance, but not as part of his analytical apparatus in the form of a "syndrome of attributes" where markets are positively characterized only in terms of "high powered incentives" and negatively described by the absence of any administrative controls. Yet, he often refers to the important role that courts have for the orderly functioning of markets. However, while he describes arbitration as a positive component of the governance structure of hybrids and likewise managerial authority as a positive component of hierarchical governance, he does not also consider market ordering by courts to be part of market governance. Yet, arbitration and managerial authority are described as functional substitutes for courts, so courts should also be seen as crucial institutional elements for the case of markets as governance structures. If one allows for the inclusion of courts as important elements of the governance structure of markets, other, private forms of market governance come into view as well, for example in the form of supervisory structures of private exchanges. Private exchanges, coincidently, are also prime examples for concrete manifestations of the abstract concept of a price mechanism.

In sum, Williamson's concept of 'market governance' seems to be curiously hollow in terms of institutional detail as compared to his other two governance structures. This, however, can be easily mended by including courts as general elements of market governance. This also brings into view private ordering variants for markets where the process of price formation is highly formalized, namely various kinds of private exchanges such as stock exchanges. We thus propose that there are various kinds of privately set-up governance structures of markets, such as private exchanges, that correspond to the private ordering forms of hybrids and hierarchies as governance structures. (For an account of the institutional evolution of private exchanges from a transaction cost perspective see Mulherin et al. 1991.)

However, this extension violates Williamson's characterization of market governance as displaying no "administrative controls" whatsoever. By contrast, hybrid forms of governance are characterized by intermediate forms of added administrative controls and hierarchical forms are assumed to have the most extensive and elaborate administrative apparatus. As we have noted above, this characterization is probably a result of Williamson's wholesale incorporation of the neoclassical market concept into his analytical framework. In fact, it seems as if 
Table 3 Commons' three types of transactions extended by a fourth type (mutual adjustment transaction)

\begin{tabular}{|c|c|c|c|c|}
\hline & $\begin{array}{l}\text { Bargaining } \\
\text { transaction }\end{array}$ & $\begin{array}{l}\text { Managerial } \\
\text { transaction }\end{array}$ & Rationing transaction & $\begin{array}{l}\text { Mutual adj. } \\
\text { transaction }\end{array}$ \\
\hline $\begin{array}{l}\text { Kind of relationship } \\
\text { involved }\end{array}$ & $\begin{array}{l}\text { Between legal } \\
\quad \text { equals }\end{array}$ & Authoritative & Authoritative & $\begin{array}{l}\text { Between legal } \\
\text { equals }\end{array}$ \\
\hline $\begin{array}{l}\text { Purpose of } \\
\text { transaction }\end{array}$ & $\begin{array}{l}\text { Sharing of } \\
\text { resources }\end{array}$ & $\begin{array}{l}\text { Production of } \\
\text { resources }\end{array}$ & $\begin{array}{l}\text { Sharing and production of } \\
\text { resources }\end{array}$ & $\begin{array}{l}\text { Production of } \\
\text { resources }\end{array}$ \\
\hline
\end{tabular}

Williamson is here describing a 'frictionless market', that is a form of completely costless economic coordination. ${ }^{5}$

Yet, we submit that our extension is ultimately consistent with Williamson's overall theoretical framework because he recognizes the role that courts play in ensuring the functioning of markets. He just sees the resultant costs as exogenous to the governance structure of markets. This then also leads to a failure to bring privately organized markets into view as an important form of economic organization. It might be interesting to apply Williamson's method of comparative analysis of discrete structural alternatives to the question under which conditions privately ordered markets, i.e. exchanges, replace publicly regulated markets. It seems that this is the case where prices need to be adjusted with a very high frequency due to rapidly changing parameters in the environment (Reimers 1996). For our present purpose, however, it suffices to state that Williamson's basic methodological device, the trading off of key properties of governance structures against properties of the business relationship, remains intact through our extension. Specifically, the "high-powered incentives" of market governance need to be traded off against efficiency advantages that often come with more specialized assets. All three types of governance structures need some kind of administrative apparatus, otherwise the very term 'governance structure' would hardly be justified. To us, recognition of this fact brings the important differences between these governance structures in terms of incentive intensity and adaptation properties to the fore in an even clearer manner. Table 4 shows and compares the four types of governance structures that result from our extension of Williamsons' theoretical framework.

\section{Compatibility of the two sets of categorical distinctions}

Juxtaposing the two systems of categorical distinctions has yielded extensions to both systems, namely by allowing for a fourth type of transaction in Commons' system, which we call a mutual adjustment transaction, and by including private

\footnotetext{
${ }^{5}$ We note that in his later work Williamson moves towards a view of markets which comes closer to our depiction; specifically, instead of characterizing markets as having no administrative controls whatsoever, he later suggested that they have "little" administrative controls (Williamson 2008, p. 8); furthermore, he later characterized market governance as being "... accomplished through competition and, in the event of disputes, by court awarded damages." (ibid., p. 9) which reflects a recognition that courts are crucial elements of market governance.
}

ordering forms of market governance in Williamson's system. In addition, we also propose an institutionally richer view of publicly regulated markets, one which includes the courts as positive elements of market governance. As a result, four types of transactions (bargaining, rationing, managerial, mutual adjustment) now need to be related to four types of governance structures (publicly regulated markets, privately regulated markets (exchanges), hybrids, and hierarchies). A one-on-one mapping remains, however, problematic. In addition to the problem mentioned above, that hybrids would be characterized in too narrow a manner if they were associated with rationing transactions only, both publicly and privately regulated markets seem to rely on bargaining transactions. However, before demonstrating how else these two extended classification systems can be related to one another, it is mandatory to ensure that any such attempt is theoretically justified, i.e. to ensure that these systems are not based on inconsistent or contradictory assumptions.

We submit that the two systems of categorical distinctions are theoretically compatible - and thus can be combined in a novel classification system - since the core assumptions made by the two authors are in complete agreement with one another. This concerns the basic unit of analysis, the nature of the main economic problem, the nature of relationships between economic actors, and lastly the preeminent role of institutions in economic life.

Both authors clearly describe the transaction as their basic unit of analysis, i.e. an economic interaction between at least two human actors rather than an isolated action of one actor directed at some economic problem. Both authors also describe the dynamic nature of economic systems as their main analytical focus rather than a concern with allocative efficiency. The dynamic nature of economic systems necessitates continuous adaptation processes and economic analyses should, according to these authors, focus on this problem. Third, both authors are also in agreement with regard to the claim that relations among economic actors are not sufficiently described by the paradigm of free and equal encounters characteristic of neoclassical economics but can involve relationships of superiority and inferiority, i.e. authority relations. Lastly, both authors agree that institutions are of preeminent importance in the regulation of individual action, i.e. it is accepted that selfinterested acting would never result in jointly beneficial economic behavior unless tamed by some kind of collectively imposed institutional constraints. This is because conflict of 
Table 4 Williamsons' three types of governance structures extended by a fourth type (private exchanges)

\begin{tabular}{lllll}
\hline & $\begin{array}{l}\text { Publicly regulated } \\
\text { market }\end{array}$ & Hierarchy & Hybrid & $\begin{array}{l}\text { Private } \\
\text { exchange }\end{array}$ \\
\hline $\begin{array}{l}\text { Kind of adaptation } \\
\begin{array}{l}\text { Ordering by/last instance of conflict } \\
\text { resolution: }\end{array}\end{array}$ & $\begin{array}{l}\text { Autonomous } \\
\text { Court }\end{array}$ & $\begin{array}{l}\text { Cooperative } \\
\text { Management }\end{array}$ & $\begin{array}{l}\text { Cooperative } \\
\text { Arbitration } \\
\text { body }\end{array}$ & $\begin{array}{c}\text { Autonomous } \\
\text { Administrative } \\
\text { body }\end{array}$ \\
\hline
\end{tabular}

interest is recognized by both authors as a basic characteristic of human relations. We also note that Williamson explicitly names Commons as one of his main intellectual sources (Williamson 1987, p. 3) and notes that Transaction Cost Economics "is responsive" to four basic characteristics that Van de Ven (1993, p. 148) used to describe Commons' intellectual contribution, namely (1) a dynamic view of institutions as a response to scarcity and conflicts of interest, (2) original formulation of the transaction as the basic unit of analysis, (3) a "part-whole analysis" of collective and individual action, and (4) an appreciation of the historical nature of institutions (Williamson 1996, pp. 220-221). We therefore conclude that there are no prima facie differences in theoretical assumptions that would invalidate any attempt to combine the categorical systems of both these authors.

\section{Combining the two sets of categorical distinctions}

For the purpose of linking the two systems of categorical distinctions, we take as our main cue Commons' suggestion that a going concern typically comprises several types of transactions, as mentioned above. While Williamson only speaks of a "resemblance" between the concept of a going concern and his notion of governance structure (1996, p. 235), we submit that there is no principal difference between these two concepts. For example, both concepts are used to refer to a firm as a form of collective action, i.e. Williamson's notion of a hierarchy as a governance structure is described by Commons as a going concern. This suggests that governance structures can also be seen as comprising various types of transactions. However, the question then arises how the notion of a governance structure as a whole is related to types of transactions as components of that unit.

\section{Governance structures as pairwise combinations of transaction types}

One way to conceptualize this relationship is by distinguishing between two levels, namely the ongoing adjustment of the rules which define a particular governance structure on the one hand and the day-to-day operations within that structure on the other hand. For example, the structure of publicly regulated markets is continually adjusted to changing circumstances through court rulings while actual market behavior corresponds to the level of operations where particular purchases are agreed and executed.
Likewise, the rules constituting a franchising arrangement as a typical example of a hybrid governance structure are frequently adjusted in response to changes in the competitive environment while daily operations, such as the performance of quality assurance checks and the procurement of supplies, occur at the level of operations within that structure. Conversely, the level of operations on a private exchange consists of transactions that are conducted according to the rules which define the exchange as a private governance structure and which may also be periodically adjusted to accommodate changes in its environment. Finally, a firm as a private governance structure consists of a set of rules such as procurement rules, hiring standards, and quality assurance procedures which may have to be adjusted in response to changes in its competitive environment. Application of and compliance with these rules then constitutes the level of operations within that governance structure.

Distinguishing between these two levels allows for a way of relating Commons' transaction types to Williamson's governance structures, including our extensions of both these systems by a fourth type of transaction and a fourth type of governance structure respectively, as depicted in Fig. 1. For completeness, we include two forms (corporatist organization and centralized planning) that we do not further consider in this paper except for a brief characterization below.

As depicted in Fig. 1, we propose that the ongoing adjustment of governance structures occurs through various instances of rationing transactions. Large-scale adjustments of firms as governance structures occur through the occasional re-organization of their divisional structure which can be seen as wholesale re-allocations of responsibilities and budgets. On a smaller scale, such adjustments occur through the annual budgeting process where divisions apply for particular budgets and are assigned particular responsibilities. Both these events can be seen as rationing transactions since they change the distribution of burdens and benefits of the collective action that constitutes the firm as a going concern. The execution of a particular budget then occurs through managerial transactions such as production planning and control decisions.

Likewise, the decisions of an arbitration body as a component of a hybrid governance structure can be viewed as instances of a rationing transaction since such decisions apportion the benefits and burden of a required adaptation to an unanticipated environmental change among the contracting parties. In their day-to-day operations, the parties rely on 
Fig. 1 Connecting Commons' and Williamson's categorical distinctions

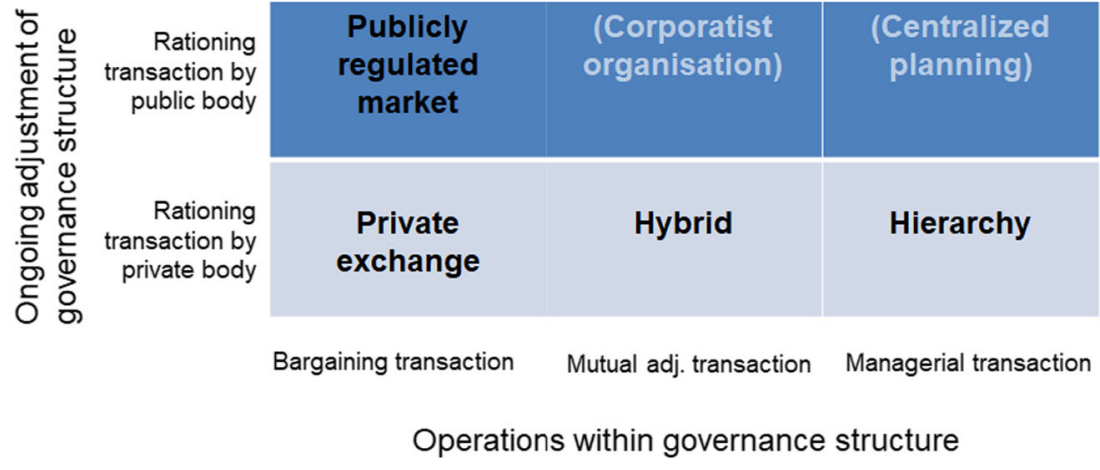

various forms of mutual adjustment transactions, including cooperative production planning and information exchange, to adapt to unforeseen changes in market environments.

The regulation of markets through courts can also be understood as an instance of a rationing transaction. Typical examples concern the sharing of liabilities in cases of damaged products as well as the adjustment of payment procedures in the context of emerging e-commerce markets. For the case of privately regulated markets, the administrative body of an exchange may adjust the rules regarding the requirements and privileges of membership, thus re-apportioning benefits and burdens among its members. Hence, supervisory bodies of private exchanges also engage in rationing transactions. Day-today trading is then conducted through various forms of bargaining transactions such as double-sided auctions.

Corporatist forms of organizing economic activities have recently received increasing attention (e.g. Kenworthy 2000; Helderman et al. 2012). According to our characterization, they can be viewed as combinations of rationing transactions by government and mutual adjustment transactions among corporatist groups. This characterization seems to fit the healthcare sector in several countries, e.g. in the Netherlands, where the state apportions resources and obligations among the various corporatistically organized professions who then mutually adjust their services to ensure the provisioning of integrated healthcare services to the public. However, a thorough examination of whether or not such a characterization accurately describes relevant economic phenomena lies outside the scope of this paper. Centrally planned economies, as instances of combining rationing and managerial transactions which, in this case, are both carried out by government, are an obvious but historically obsolete form of organizing economic activities.

Centralized planning by communist and fascist dictatorships, the corporate budgeting process as well as decisions by arbitration bodies and the courts are explicitly mentioned by Commons as instances of rationing transactions (Commons 1931, pp. 653-654).

Rationing transactions thus acquire a special status among the four types of transactions in that they continually adjust the foundation on which the other transaction types - bargaining, mutual adjustment and managerial transactions - can then operate. This may account for the fact that Commons remained ambivalent regarding the question of whether a rationing transaction serves the purpose of combining resources or of sharing resources whereas he clearly specified that bargaining transactions serve the purpose of sharing resources while managerial transactions are aimed at combining resources, i.e. at joint production processes. (Our addition, the mutual adjustment transaction, also unambiguously serves the purpose of combining resources.) According to our proposed classification scheme, rationing transactions are involved in both these purposes which would explain Commons' ambivalence in this regard.

Our extended classification scheme thus connects the two categorical classification systems of Commons and Williamson by distinguishing between the two levels of adjusting the rules that make up a particular governance structure on the one hand and of operating within that structure on the other hand. The resultant classification not only complies with the empirical facts cited by Williamson to characterize the three governance structures of (publicly regulated) markets, hierarchies, and hybrids but also offers a theory-based definition of these structures, namely as pairwise combinations of various transaction types. (In the appendix, we briefly discuss other proposals to extend Williamson's system of categorical distinctions.)

\section{Benefits of a more general characterization of governance structures}

Our analysis so far has yielded a classification system of forms of economic organization that combines and extends the categorical distinctions made by Commons and Williamson. This has brought into view a form of economic organization neglected by Williamson, namely private ordering of markets, which may be seen as a theoretical contribution in itself. However, the real pay-off of our analysis for the purposes of the present paper is that our novel classification scheme provides a more general description of forms of economic organization that are not tied to specific institutional, and thus historically contingent, arrangements. By contrast, the notions of markets, hybrids, and hierarchies are closely tied to historically contingent institutional 
arrangements, not least through Williamson's association of each form with a specific type of contract law. This also means that novel economic phenomena such as two-sided markets are first seen through the lens of these contingent forms, e.g. as firms or as traditional markets. Therefore, in order to fully grasp the novel nature of these phenomena, it may be necessary to abstract from concrete institutional detail by reverting to a more general categorical system which, nevertheless, is still rooted in an institutional perspective of economic phenomena. Commons, we argue, provides us with such categories in the form of his distinction between various types of transactions.

Conversely, the notion of "syndromes of attributes" to characterize governance structures in functional terms seems to be too general to positively characterize and discriminate between emerging new forms of economic organization, especially in view of the potential weakness in Williamson's characterization of governance structures concerning the attribute of 'extent of administrative controls' that we have identified above. Specifically, we have argued that administrative controls, in the form of court rulings, are also an integral component of publicly regulated markets so that 'extent of administrative controls' cannot serve as a criterion to distinguish between various governance structures. That leaves only three attributes to characterize governance structures, namely incentive intensity, performance properties in terms of adaptation of type $\mathrm{A}$ and $\mathrm{C}$, and underlying contract law. Contract law may turn out to be insufficient to address the challenges of emerging forms of economic organization for the reasons outlined above and thus cannot be used to positively characterize these forms. The two types of adaptation essentially refer to different coordination mechanisms (price vs. some kind of cooperative form) and, as such, are less precise than Commons' transaction types. Similarly, incentive intensity characterizes the three forms of governance in a rather rough manner, as a more or less in terms of incentive intensity, and thus does not afford a clear distinction between the three forms. It is only after a governance structure has been identified that its incentive intensity can be evaluated vis-à-vis the other two governance structures but one cannot infer, from a given level of incentive intensity, which governance structure is involved.

We do not propose that our analysis invalidates Williamson's general argument or the many applications of his theoretical framework but suggest that his categorical distinctions are not sufficient when the issue are emergent forms of economic organization for which the extant institutional environment may turn out to be ineffective. In other words, as long as the concern is with a comparative analysis of extant forms of governance, Williamson's analytical framework has turned out to be effective and to have yielded robust results (Williamson 2008). However, application of his main ideas to emergent forms of economic organization requires a re-formulation of his main conceptual apparatus that abstracts from institutional details which have evolved to shape our present-day dominant forms of economic organization.

\section{Two-sided markets as instances of generic forms of governance structures}

We propose that various kinds of two-sided markets can be distinguished based on our classification scheme, distinctions which so far have not been paid attention to in the literature and which may turn out to be crucial for understanding, and eventually regulating and managing, these new forms of economic organization. Moreover, characterizing two-sided markets in terms of our classification scheme also reveals these new forms as functional alternatives to presently dominant forms of economic organization (which we will refer to as 'traditional forms' in the following). This then allows for specifying propositions regarding the role of technology in possible shifts to these new forms in the spirit of the "move-to-the-market hypothesis" (Malone et al. 1987), also known as the "electronic market hypothesis" (Wigand 2011), by drawing on Williamson's method of identifying trade-offs between discrete institutional forms of economic organization.

Since two-sided markets are exclusively privately organized forms of economic organization, we only consider one kind of rationing transaction in the following analysis, namely rationing transactions by private bodies. Thus, the upper half of our classification scheme, which comprises publicly regulated markets, corporatist forms of economic organization, and centrally planned economies, is no longer relevant for our analysis. Our basic proposition is that three distinct forms of two-sided markets can be distinguished which, while all three are created and adjusted through private rationing transactions, differ with regard to the transaction type used at the operational level. Fig. 2 shows our classification of two-sided markets. In the following, we will justify and illustrate our classification for each of these three forms.

\section{Online trading platforms}

Online trading platforms, such as eBay or Taobao, combine rationing and bargaining transactions. Through rationing transactions, the rights and obligations of its members are defined and periodically adjusted. Within these rules, members then conduct bargaining transactions the concrete form of which is also defined by the rules of the platform, e.g. through various kinds of auctions. Online trading platforms are the online version of traditional private exchanges. In fact, traditional exchanges would be classified as prominent cases of two-sided markets had that term not mostly been reserved for IT-enabled organizational phenomena. Hence the analysis of such markets carries over to online trading platforms in various ways. For example, a prominent topic in the analysis of exchanges concerns the question how member-owned exchanges differ from exchanges owned by outsiders in terms of efficiency properties. Hart and Moore (1996) argue that member-owned exchanges become relatively less efficient as the environment becomes more competitive. Pirrong (1999) has shown that member- 
Fig. 2 Classifying two-sided markets

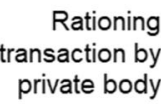

Online trading

platform

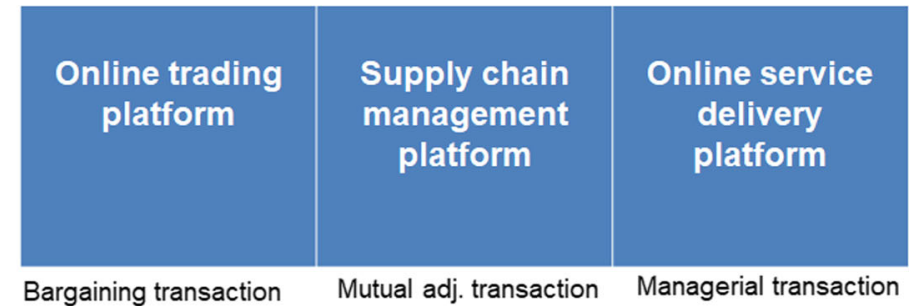

Bargaining transaction thus apportioning benefits and burdens among its members, i.e. it also conducts rationing transactions. For example, in 2014 Uber has lowered prices in Germany, responding to ongoing legal disputes with local taxi services, thus shifting benefits from drivers to clients. ${ }^{7}$ Viewing online service delivery platforms such as Uber as institutional alternatives to hierarchical governance is also corroborated by several court rulings regarding Uber. Specifically, in 2015, various court rulings in the US have upheld a decision by the California Employment Development Department against Uber to treat Uber drivers as employees of Uber, not as independent contractors. ${ }^{8}$ However, viewing Uber drivers as employees also shows that the legal apparatus has not yet been adapted to that new phenomenon as there are clear differences between members of such platforms and employees of firms, a topic to which we will come back below.

\section{Supply chain management platforms}

A further phenomenon, which now reveals itself as an instance of an IT-enabled two-sided market, concerns new forms or organizing economic activities which we call supply chain management platforms. Rooted in modest beginnings where companies connected their internal information systems to create so-called inter-organizational information systems (IOIS) (Cash 1985), supply chain management platforms increasingly facilitate cooperation across whole industries. For example, RosettaNet, a consortium of firms in the IT, electronic components and semiconductor industries, develops standards that facilitate the interlinking of internal production planning systems to form an IOIS which facilitates various forms of joint production planning processes (Löwer 2006). In contrast to other industry consortia that promote so-called Electronic Data Interchange (EDI) in a standardized manner, RosettaNet not only specifies syntactic and semantic standards for interconnecting systems but also prescribes the exact choreography of interactions between systems in order to enable timely responses to market changes along a whole supply chain; for example, these standards define maximum response times for specific kinds of messages such as purchase order requests (ibid.). RosettaNet thus engages in rationing transactions by apportioning burdens - e.g. the maximum time allowed to respond to some electronic message - and benefits - e.g. shorter

\footnotetext{
8 "Uber Driver Declared Employee as the Company Loses another Ruling," The Guardian, September 11, 2015.
} 
lead times - among supply chain members. These then enable supply chain firms to jointly engage in cooperative forms of production planning which are instances of mutual adjustment transactions. In contrast to production planning in firms or on online service delivery platforms, which we characterize as instances of managerial transactions, members of a supply chain management platform cannot appeal to a super-ordinate authority in cases of conflict over production planning options but must do so through mutual agreement (VICS 2010). The authoritative relations that are established through membership in the RosettaNet consortium only concern obligations to comply with certain interface standards, not to particular solutions of adjusting production plans along the supply chain.

\section{The three kinds of platforms as two-sided markets}

All three forms qualify as two-sided markets. As reviewed above, a two-sided market is defined as an arrangement where an intermediary brings together two distinct 'user groups' who provide each other with network benefits. Online trading platforms and online service delivery networks are often quoted examples of two-sided markets. Supply chain management platforms also clearly fall into the category of two-sided markets. For example, the different user groups of the RosettaNet consortium are groups of firms at the various supply chain stages who, through complying with certain interfacing requirements, provide each other with network benefits related to coordinating production planning: The more companies comply with a particular interface specification the higher the value of participation in the network as a whole becomes. Standardization bodies such as RosettaNet can therefore be seen as the actors that bring together these user groups.

\section{Examining the relationships between the three forms of two-sided markets from a williamsonian perspective}

While we have taken care in the development of our extended classification scheme to remain consistent with the basic assumptions that both authors have made in developing their systems of categorical distinctions, we must also ensure that our extended classification scheme still complies with the basic logic of Transaction Cost Economics (TCE) lest we risk to appropriate that theory in an inauthentic manner (Lee 2016; Lacity and Khan 2016; Aubert and Rivard 2016). The main hypothesis of TCE is that "transactions, which differ in their attributes, are aligned with governance structures, which differ in their adaptive strengths and weaknesses, so as to accomplish a transaction cost economizing result." (Williamson 2008, p. 9). Transactions differ mainly with regard to the attributes of asset specificity, uncertainty, and frequency but TCE focuses on asset specificity in the face of a positive degree of market uncertainty (ibid., p. 8). Governance structures mainly differ with regard to their ability for adaptation with regard to the two types of adaptation (autonomous and cooperative) as described above and with regard to their incentive intensity.

Since our classification suggests that the three types of twosided platforms are functional alternatives to traditional forms, Williamson's main hypothesis should also apply to these new forms. However, as Williamson did not consider exchanges as privately ordered forms of market governance our evaluation must be limited to asking whether shifts from publicly regulated markets to supply chain management platforms, as alternatives to hybrids, and from there to online service delivery platforms, as alternatives to hierarchies, can be explained by the same logic.

In view of the above summary of TCE, a notable difference between the traditional forms described by Williamson and our characterization of two-sided markets comes to mind when comparing hybrids and supply chain management platforms. Hybrid forms are characterized by significant degrees of asset specificity that require institutional safeguarding, e.g. in the form of penalties, information disclosure requirements, and conflict resolution mechanisms such as arbitration (Williamson 2008). By contrast, supply chain management platforms prescribe standard ways of interconnecting systems and practices, thus eliminating the need for specific interfaces and practices, arguably the main sources of asset specificity in supply chains (Daniel and White 2005). Thus, it seems that the main factor which determines the alignment between transaction characteristics and governance structures is neutralized for the case of supply chain management platforms.

However, we argue that asset specificity in supply chain management platforms is not entirely eliminated but only mitigated. Electronic interfacing standards such as those developed by the RosettaNet consortium cannot ensure that business partners can be costlessly replaced but they mitigate the degree of mutual dependence that is created through the interconnection of internal systems. The most important aspect of such interconnecting does not concern the structure of electronic messages or even the meaning of codes used in such messages, but the alignment of business processes that underlie a smooth coordination between business partners (Kubicek 1992; Horlück 1994). Electronic interfacing standards thus serve to re-establish a certain degree of interchangeability of business partners that would otherwise be lost. In other words, electronic interfacing standards ensure that the 'high powered incentives' of markets remain effective in supply chains to some degree in the face of ever deeper integration of information systems. Such market elements are lost in online service delivery platforms. Here, the members are tied to the platform provider and the systems of platform members become completely aligned with the requirements dictated by the platform provider. The fact that platform members are willing to enter into such highly dependent business relationships is one of the most interesting aspects of this new form of economic organization. As mentioned above, courts presently tend to interpret such relations in terms of labor law as they see similar 
degrees of dependency between members of online service delivery platforms and employees of firms.

To conclude, we claim that Williamson's logic also applies to our types of two-sided markets. As degrees of asset specificity increase, more elaborate forms of coordination are used to accommodate the requirements of cooperative forms of adaptation at the expense of ever weaker market incentives.

\section{The role of IT in possible shifts to two-sided markets as novel forms of economic organization}

Our analysis has yielded a generic classification scheme of governance structures which accurately describes traditional forms of economic organization, including those described by Williamson, and, when applied to two-sided markets, brings out three distinct types of such forms, distinctions which have hitherto not been paid attention to. Moreover, the overall logic of TCE reasoning also applies to two of these forms while for the third (online trading platforms) there is no equivalent form in traditional Transaction Cost Economics. We therefore find that our classification scheme offers a valid way of conceptualizing two-sided markets from an institutional perspective, specifically from a TCE perspective.

While we envisage applications of our new classification scheme to various areas of economic and organization theory such as regulation and management, in an IS context an urgent question is whether a general IT-induced 'shift' from traditional forms to these new forms, i.e. to two-sided markets, is about to happen given that these new forms can be seen as functional equivalents of traditional forms, as we have claimed above. In the spirit of the "electronic market hypothesis (Malone et al. 1987), which predicted a general IT-induced shift from hierarchical forms to market-based forms of governance, a claim which has received mixed empirical support (Holland and Lockett 1993; Clemons et al. 1993; Brynjolfsson et al. 1994; Phelps 2007) and which has been extended in various ways (Christiaanse et al. 2004; McAfee et al. 2007; Lee et al. 2008; de Corbière and Rowe 2013; Fink 2013) but which has not yet been refuted (Wigand 2011), we explore possible drivers and inhibitors of such a shift from traditional to modern forms of organizing economic activities.

\section{Avoiding technological determinism}

The main challenge for formulating propositions that concern the role of information technology in supposed shifts among forms of organizing economic activities is this: any technology that 'enables' a new form of organizing economic activity could, in principle, also strengthen extant forms. Thus, the fact that a certain technology enables a new form does not suffice to predict that a corresponding shift to that new form will actually happen. A major strength of the original formulation of the electronic market hypothesis by Malone et al. (1987) is that it has accommodated for this double-effect by arguing that markets benefit relatively more from the use of information technology than hierarchies. A weakness of that claim can be seen in its deterministic character as the hypothesis predicts an inevitable shift from hierarchies to markets under the influence of increased information technology use, a weakness which may partly account for the inconclusive empirical findings so far.

In order to avoid such technological determinism we seek to formulate our propositions in a way that does not imply an inevitable and relentless application of information technology for the purpose of modifying forms of economic organization to become more like two-sided markets. Instead, we wish to identify the conditions under which such application is likely and, conversely, under which it is detrimental for the effective organization of economic activities. For this purpose, we adopt Williamson's main methodological device of identifying trade-offs between various distinct institutional forms to isolate the factor or factors that decide how these trade-offs work out in each concrete situation. For Williamson, this factor is mainly asset specificity, the trade-offs exist between the high-powered incentives of market governance on the one hand and the superior adaptability properties of cooperative forms of governance in view of unanticipated changes in the environment on the other hand. Williamson also assumes that high degrees of asset specificity normally imply more efficient production processes in some specific context. In the following, we will use this general set-up as our cue for constructing a similar argument that yields a testable hypothesis regarding the conditions under which application of information technology to support new forms of economic organization, viz. two-sided markets, becomes likely.

\section{Algorithmic separability}

We have constructed our classification scheme by distinguishing between the level of ongoing adjustments of the rules that define a particular governance structure and the level of day-to-day operations within that governance structure. This has allowed us to describe governance structures as pairwise combinations of transaction types. We now again start from that idea by proposing that one effect of the application of information technology for the purpose of enabling new forms of economic organization such as two-sided markets is to allow for a relatively stronger separation between these two levels: As organizational rules become enshrined in algorithmic form on IT-enabled two-sided markets, adapting such rules to concrete situations becomes much more difficult. On the one hand, these rules are now presented to organizational members in the form of specific instructions for action in concrete situations. For example, the Uber algorithm instructs drivers to pick up a specific client at a specific location and does so all the time. On the other hand, compliance with such instructions is now recorded in real-time and 
in a manner which allows for easy detection of non-compliance. By contrast, traditional taxi drivers are much more flexible with regard to where to seek customers and which customers to pick up. They can thus adjust their actions more flexibly to the situation in which they currently find themselves, including possibilities for re-negotiating prices, even though prices are supposedly fixed in most cases by organizational rules, since such deviation from the rules is not so easy to detect.

To be sure, technology is not the only factor that contributes to a cleaner separation between the two levels. Others include organizational and institutional characteristics of two-sided markets. For example, in hierarchical governance structures which, according to our classification scheme, are a functional equivalent of online service delivery platforms, there is normally a career path that connects the operational levels, where organizational rules are applied, to the management level, were these rules are defined and adjusted. Moreover, the relationship between managers and subordinates generally allows for a much richer interaction that also enables mutual influencing. By contrast, on online service delivery platforms there is no career path from the operational level, the drivers, to the management level and drivers and managers also normally do not interact in person. Rather, their interactions are entirely structured and mediated by organizational rules which are embedded in algorithmic form on the platform.

Regarding the case of supply chain management platforms, which we see as functional equivalents of hybrid governance structures, the organizational rules are defined by a standardization body which itself operates according to published procedures and principles so that it becomes much harder to adjust organizational rules to specific situations. Moreover, their embeddedness in electronic forms of interchange makes detection of non-compliance relatively easy. By contrast, in hybrid forms of governance companies can more easily re-define the rules which they have given themselves to structure their business relationship. However, the effectiveness of hybrid governance structures also depends on their ability to prevent opportunistic behavior ex post so that the rules which have been defined ex ante must display a certain sturdiness in the face of un-anticipated opportunities for one of the parties to renegotiate the terms of the trade. Such sturdiness is described by Williamson as the ability to make credible commitments.

Finally, regarding online trading platforms, functional equivalents to traditional private exchanges, the main institutional device for more clearly separating the two levels of ongoing rule adjustment and day-to-day rule application consists of separating ownership from organizational membership. The literature on traditional exchanges has extensively discussed the advantages of outside ownership over member-owned exchanges, concluding that outside ownership tends to make trading regimes more efficient (see above). Online trading platforms are normally set up by entrepreneurs and hence usually use outside ownership. Thus, to the extent that traditional exchanges are owned by outsiders the two levels are already institutionally separated. By contrast, most exchanges already make extensive use of information technology to track and trace trading behavior of market participants so that a shift to online trading is unlikely to make organizational rules more rigid as a result of enshrining these rules in algorithms. As pointed out above, traditional private exchanges would be characterized as instances of two-sided markets had that term not been invented in the context of IT-enabled forms of organizing economic activities.

In conclusion, while application of information technology to enabling two-sided markets as new forms of organizing economic activities contributes to a clearer separation between the level of ongoing adjustment of organizational rules and the level of day-to-day application of such rules, an effect which we term 'algorithmic separability', this is not the only factor in this regard. On two sided-markets, such use of technology tends to be reinforced through organizational and institutional means, a kind of separation which, among traditional forms, is most visible for the case of private exchanges.

\section{Parametric predictability}

A clearer separation between these two levels has advantages and disadvantages, i.e. there is a trade-off in pushing for a stricter separation. Specifically, the stifling of attempts to soften or modify organizational rules which is associated with a clearer separation between the two levels has two opposite effects: On the one hand it prevents actors from undermining organizational rules for private profit through lobbying, rent-seeking and the like; on the other hand, it also makes it more difficult for actors to adapt organizational rules to the specific situation at hand when such adaptation would improve economic performance. We call this kind of adaptability 'interpretive flexibility' because actors are able to interpret organizational rules with a view to the spirit of the rules rather than in accordance with the letter of the rules. It follows that the advantages of a relatively clearer separation of the two levels dominate associated disadvantages when flexibility of interpretation of organizational rules is not necessary or only a minor concern because then the efficiency gains that are associated with less 'wiggle room' for interpreting organizational rules can be fully utilized. Conversely, the disadvantage of more clearly separating the two levels come to dominate its advantages as the need for situational interpretation of organizational rules increases.

We surmise that one important factor which determines whether there is such a need for flexible interpretation of organizational rules is the 'messiness' of an industry. Specifically, we propose that one of the factors that will influence whether there will be a shift to modern, i.e. IT-enabled forms of economic organization consists in the ease of defining rules contingent on anticipated changes in the economic environment. Formally we define a factor 'parametric predictability', and its inverse: parametric unpredictability, to capture this idea. Given that economic actors face a dynamic environment, there will be some changes 
that are parametric in nature, i.e. actors know in advance which environmental factors are important and they also know that changes in these factors are of a continuous kind. Organizational rules can therefore be calibrated to such changes, within certain bounds. For example, actors know that the quantity of demand for a product may oscillate within certain bounds and therefore can define organizational rules in such a way that such oscillations are accommodated for. However, the kind of the product that will be in demand is known to the actors. By contrast, parametric unpredictability means that either the factors which will turn out to be important are not yet known or that changes in factors which are known to be relevant are discontinuous in nature. For example, companies in the textile industry all know that color is one of the main factors that will drive demand. However, color is a discontinuous variable: if it turns out that consumers like bluish green, then all sweaters colored in yellowish green can only be sold at a steep discount while it will be almost impossible to replenish the quickly selling blueish green sweaters. In other cases, companies may not even be sure about the nature of the product they will be selling in the near future.

We believe that it is no coincidence that one of the first and most prominent examples of an online service delivery platform concerns taxi services. All environmental changes in the taxi industry have the characteristic of parametric predictability. There may be an unanticipated spike in demand at a certain location in the city, but it will still be individual people who need to get a lift and it will be more or fewer people. At the same time, casual observation suggests that there is a huge efficiency gain lying dormant in the industry when one observes long rows of taxis cuing up at neuralgic spots waiting for customers. The same observation, of course, holds for many branches of the retail and the service industries in which

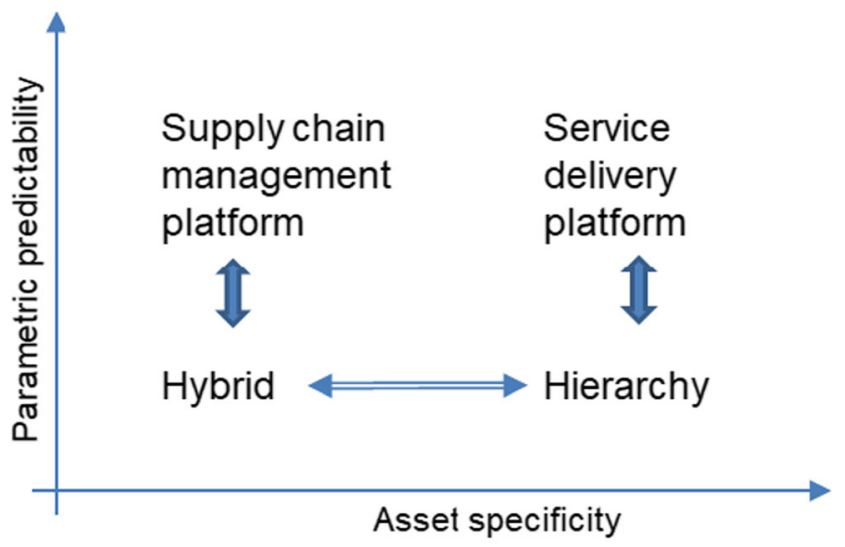

Williamson's hypothesis

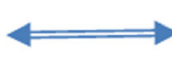

Our proposition

Fig. 3 Relationship between our proposition and Williamsons' hypothesis online service delivery platforms are sprouting too. By contrast, textile supply chains seem to be dominated by large hierarchical firms and by hybrid forms of governance structures regulating relationships involving many small firms (Yuan 2007). The car industry, which is driven by product innovation like few other industries, likewise seems to be a reluctant adopter of two-sided markets as substitutes for large hierarchies and hybrid forms of governance.

Figure 3 summarizes our proposition and shows how it relates to Williamson's hypothesis. It only depicts those governance structures for which both Williamson's hypothesis and our own proposition hold simultaneously. Williamson does not consider traditional or online exchanges while our proposition only concerns private forms of ordering and thus excludes publicly regulated markets as governance structures. Williamson predicts a shift towards more integrated governance structures as the degree of asset specificity increases. We predict a move towards twosided markets as the degree of parametric predictability increases. The reason is that two-sided markets, as governance structures, display a greater degree of separation between the level of ongoing adjustments of a governance structure on the one hand and the level of day-to-day operations within that governance structure on the other hand. As parametric predictability increases, the efficiency gains that are associated with a greater degree of separation begin to dominate its disadvantages, a loss of interpretive flexibility characteristic of traditional forms. IT plays a significant role as it contributes to a greater separation between these two levels thanks to a property which we have characterized as algorithmic separabilitiy and thus acts as an enabler for this possible shift towards modern forms of economic organization.

\section{Limitations}

We want to briefly discuss three limitations that potentially limit the validity and reach of our argument. The first concerns our decision to only consider pairwise combinations of transaction types as generic governance structures whereas Commons had indicated that all three types distinguished by him could possibly be combined in a complex form of a going concern, i.e. governance structure. What comes to mind is the possibility of creating 'internal markets' in firms by allocating some resources through a competitive bidding mechanism, i.e. by using bargaining transactions in firms. While Williamson has argued that such internal markets must, in all cases, remain ineffective because the 'market participants' can never be sure whether any resultant allocation will not be overruled by management fiat, companies certainly claim to have created such internal markets. Moreover, our addition of the mutual adjustment transaction captures organizational phenomena that may be collectively characterized as forms of team-based organization and that are important phenomena in modern firms. Thus, our classification scheme is limited by the fact that it 
only considers pairwise combinations of transaction types while a casual survey of organizational phenomena suggests that more complex forms do, indeed, exist.

A second limitation concerns the number and kind of coordination mechanisms involved. Whereas Williamson only distinguishes two, autonomous and cooperative adaptation, and Commons three, bargaining, managerial, and rationing transactions, it is quite clear that even our extension by a fourth type does not exhaust the range of organizational phenomena. For example, organization theory has developed a much more granular classification system distinguishing, e.g., between process standardization, planning, and direct supervision (Mintzberg 1979), all of which would have to be classified as variations of managerial transactions in our and Commons' system. Malone and colleagues have even undertaken to develop a science of coordination and set out by empirically collecting all kinds of varieties of coordination mechanisms (Malone and Crowstone 1994). The kind of limitation which results from limiting the number of distinct coordination mechanisms to four is the same that results from our limitation to considering only pairwise combinations of transaction types as governance structures. There may simply be many more organizational forms which our classification scheme is incapable of capturing. Moreover, it might be the case that some coordination mechanisms benefit 'relatively more' from information technology than others, to generalize the argument made by Malone et al. (1987). To the extent that this is the case, our proposition regarding possible shifts between traditional and modern forms of organization may be affected up to the point where the very distinction between traditional and modern forms becomes meaningless or invalid.

Lastly, by drawing on Commons' distinction between types of transactions we have ignored one of the principles that he uses to characterize economic relationships. The three types of transactions, as well as our addition of mutual adjustment transactions, concern only the first two principles described by Commons, namely the principle of scarcity, related to the task of sharing resources, and the principle of efficiency, related to the task of combining resources. The third principle, the principle of futurity, is implied in our classification scheme to the extent that all organizational forms, i.e. going concerns, need to be based on an expectation of orderly ongoing transactions in the future by all actors involved in a transaction. However, we have not worked out what this principles implies, specifically with regard to possible shifts between traditional and modern forms. The principle of futurity seems to be especially relevant in such instances since any such shift puts an extra burden on the actors in terms of their confidence in a continuation of orderly transactions in the future when it becomes clear that future transactions may be organized in a radically different manner. This limitation concerns the nature of Williamson's theoretical approach, namely the comparison of institutionally distinct forms of economic organization in view of their transaction cost outcomes. Any prediction based on such an analysis assumes that the relatively more transaction cost-efficient organizational form is 'selected' by the economic environment, an assumption which may not hold. As Ciborra (1996) has argued, Williamson's analysis is incapable of describing how actors move from one institutional form to another since "transition costs" or, more broadly, organizational learning is not considered. The same limitation applies to our analysis. In an interesting comment on "disappointments" with regard to outsourcing arrangements, Williamson (2008, p. 13) lists a number of human failures of anticipation and institutional safeguarding that may explain such disappointments. The initial wave of outsourcing was characterized by high expectations and, to some degree, by hype. Presently, we observe a similar hype regarding two-sided markets in their many varieties. Consequently, a similar overshooting may result and it will take some time until the transaction cost efficient governance forms will have been selected and inefficient forms 'unselected', if that ever happens. The phenomenon of 'hype' seems to bear an interesting and relevant relationship with Commons' principle of futurity that is well worth exploring in future research. For our paper, however, neglecting that principle in our analysis means that our proposition also must assume an effective environmental selection mechanism, an assumption which may not be warranted, at least in the short term.

\section{Conclusions}

Such new phenomena as Uber and Taobao as large-scale platforms that come to organize and even dominate whole industries not only put anti-trust authorities and managers of incumbent firms on high alert but may also herald a largescale shift in how economic activities are organized, possibly comparable to the rise of the giant, vertically integrated industrial firm which arose in the tracks of new technologies in the nineteenth century, the railroad and the telegraph, as analyzed by Alfred Chandler. The phenomenon has been extensively analyzed from a neoclassical economic perspective under the name of two-sided markets. However, this literature increasingly turns the concept of two-sided markets into an analytical tool and thus risks losing sight of the very phenomenon itself. In this paper, we have made an attempt to bring the phenomenon into full view again and have done so from an economic institutional perspective by drawing on Williamson's Transaction Cost Economics and Commons' Institutional Economics. In so doing, we have made five contributions. First, we have extended fundamental categorical distinctions made by Commons, one of Williamson's main sources of inspiration, and by Williamson. Second, we have created a novel classification scheme by combining these extended categorical distinctions to describe six generic forms of economic organization and shown that this scheme provides a more general 
characterization of governance structures than Williamson's three types (markets, hierarchies, and hybrids). Third, we have shown that two-sided markets are instances of these generic forms which allowed us to distinguish three distinct forms of two-sided markets, a distinction which has not yet been made. Fourth, we have demonstrated that these instances of two-sided markets are functional substitutes for the three governance structures described by Williamson. Fifth, we have developed some first ideas regarding the factors that could explain possible shifts from traditional forms of economic organization, Williamson's three governance structures, to these modern forms presently known as two-sided markets.

These are tentative ideas and our main purpose with this paper is to stimulate a new round of scholarly debate about the role of information technology in the transformation processes that we are currently witnessing and experiencing and that was initiated 30 years ago by the proponents of the electronic market hypothesis.

Acknowledgements We would like to thank the two reviewers for their immensely helpful suggestions and critique as well as the Associate Editor for his careful and clear guidance. This work was supported by the National Natural Science Foundation of China (grant numbers 71110107027, 71572092, 71490721, and 20161351032) as well as by the Ministry of Education Project of the Key Research Institute of Humanities and Social Sciences at Universities (17JJD630006).

\section{Appendix: other proposals to extend Williamson's classification system}

Other ways of extending Williamson's distinction between markets, hierarchies, and hybrids have been proposed in the literature. From a sociological and managerial perspective, a number of proposals have been made which share the same basic argument, namely that relationships among economic actors are not only based on a narrow economic or legal rationale but also on social mechanisms that recognize the social nature of human beings. These include Ouchi's (1980) concept of clans, Granovetter's (1994) concept of business groups, Ciborra's (1996) 'teams and markets approach', and various proposals which are collectively addressed as the 'Swedish Network Approach' (Johanson and Mattson 1987). These proposals tend to juxtapose economic and social aspects of economic relationships. They can be characterized as efforts to offer a richer and more precise description of contemporary phenomena but lack the analytical capabilities of economic institutional theories that link certain economic problems with particular institutional arrangements.

From a legal perspective, Hodgson argues that Williamson's distinction between markets, hybrids, and hierarchies fails to take into account that there is a fundamental difference between "proper" or "pure" markets and long-term relationships between firms. He even argues that the latter do not involve market transactions at all and proposes to call such arrangements "relational exchanges" or "non-market exchanges" because their purpose is not the one-time exchange of a product or service, as in "proper" markets, but the maintenance of a business relationship (Hodgson 2002). However, while his distinction between short-term relationships and relational exchange is clearly important and descriptively accurate, he also does not offer an analytical apparatus for linking forms of economic organization with fundamental problems of allocating resources. Instead, his categories are purely descriptive, like those of the above mentioned managerial and sociological approaches, albeit formulated from a legal or institutional perspective.

Open Access This article is distributed under the terms of the Creative Commons Attribution 4.0 International License (http:// creativecommons.org/licenses/by/4.0/), which permits unrestricted use, distribution, and reproduction in any medium, provided you give appropriate credit to the original author(s) and the source, provide a link to the Creative Commons license, and indicate if changes were made.

\section{References}

Aubert, B. A., \& Rivard, S. (2016). A Commentary on: "The Role of Transaction Cost Economics in Information Technology Outsourcing Research: A Meta-Analysis of the Choice of Contract Type". Journal of Strategic Information Systems, 25, 64-67.

Brynjolfsson, E., Malone, T. W., Gurbaxani, V., \& Kambil, A. (1994). Does Information Technology Lead to Smaller Firms? Management Science, 40(12), 1628-1644.

Cash, J. I. (1985). Interorganizational Systems: An Information Society Opportunity or Threat? The Information Society, 3(3), 199-228.

Chandler, A. D. (1980). The Visible Hand: The Managerial Revolution in American Business. Boston: Harvard University Press, first published 1977.

Christiaanse, E., van Diepen, T., \& Damsgaard, J. (2004). Proprietary Versus Internet Technologies and the Adoption and Impact of Electronic Marketplaces. Journal of Strategic Information Systems, 13(2), 151-165.

Ciborra, C. U. (1996). Teams, Markets and Systems - Business Innovation and Information Technology. New York: Cambridge University Press, first published 1993.

Clemons, E. K., Reddi, S. P., \& Row, M. C. (1993). The Impact of Information Technology on the Organization of Economic Activity: The "Move to the Middle" Hypothesis. Journal of Management Information Systems, 10(2), 9-36.

Commons, J. R. (1931). Institutional Economics. American Economic Review, 21(4), 648-657.

Commons, J. R. (1990). Institutional Economics - Its Place in Political Economy, Vol. 1. New Brunswick, London: Transaction Publishers, first published 1934.

Corbière, F. de \& Rowe, F. (2013). From Ideal Data Synchronization to Hybrid Forms of Interconnections: Architectures, Processes, and Data. Journal of the Association for Information Systems, 14(10).

Daniel, E., \& White, A. (2005). The Future of Inter-Organisational Systems Linkages: Findings of an International Delphi Study. European Journal of Information Systems, 14(2), 188-203.

Farrell, J., \& Saloner, G. (1985). Standardization, Compatibility, and Innovation. RAND Journal of Economics, 16(1), 70-83.

Fink, L. (2013). The Logic of Electronic Hybrids: A Conceptual Analysis of the Influence of Cloud Computing on Electronic Commerce. 
Journal of Theoretical and Applied Electronic Commerce Research, $8(3), 1-11$.

Gallaugher, J. M., \& Wang, Y.-M. (2002). Understanding Network Effects in Software Markets: Evidence from Web Server Pricing. MIS Quarterly, 26(4), 303-327.

Granovetter, M. (1994). Business Groups. In N. Smelser \& R. Swedberg (Eds.), Handbook of Economic Sociology (pp. 453-475). Princeton: Princeton University Press.

Hart, O., \& Moore, J. (1996). The Governance of Exchanges: Members's Cooperatives vs. Outside Ownership. Oxford Review of Economic Policy, 12(3), 53-69.

Helderman, J.-K., Bevan, G., \& France, G. (2012). The Rise of the Regulatory State in Health Care: a Comparative Analysis of the Netherlands, England and Italy. Health Economics, Policy, and Law, 7(1), 103-124.

Heng, M. S. H. (2003). Understanding Electronic Commerce from a Historical Perspective. Communications of the AIS, 12, 104-118.

Hodgson, G. M. (2002). The Legal Nature of the Firm and the Myth of the Firm-Market Hybrid. International Journal of the Economics of Business, 9(1), 37-60.

Holland, Ch.P. \& Lockett, G. (1993). Mixed Mode Operation of Electronic Markets and Hierarchies. In M. Ebers (Ed.): Proceedings of the Workshop on Inter-Organizational Networks Structures and Processes, Berlin 6-7 September 1993, pp. 524-552.

Horlück, J. (1994). The Pragmatics of Electronic Data Interchange: The Use of EDI will Unify Business Procedures. International Journal of Information Management, 14, 330-343.

Johanson, J., \& Mattson, L.-G. (1987). Interorganizational Relations in Industrial Systems: A Network Approach Compared with the Transaction-Cost Approach. International Studies of Management and Organization, 17(1), 34-48.

Katz, M. L., \& Shapiro, C. (1985). Network Externalities, Competition, and Compatibility. The American Economic Review, 75(3), 424-440.

Kaufman, B. E. (2003). The Organization of Economic Activity: Insights from the Institutional Theory of John R. Commons. Journal of Economic Behavior \& Organization, 52(1), 71-96.

Kaufman, B. E. (2007). The Institutional Economics of John R. Commons: Complement and Substitute for Neoclassical Economic Theory. Socio-Economic Review, 5, 3-45.

Kenworthy, L. (2000). Quantitative Indicators of Corporatism: A Survey and Assessment. Discussion Paper No. 00/4, Cologne. Max Planck Institute for the Study of Societies.

Kubicek, H. (1992). The Organization Gap in Large-Scale EDI Systems. In R. J. Streng et al. (Eds.): Scientific Research on EDI - "Bringing Worlds Together", Proceedings of the EDISPUUT Workshop, May 6th and 7th, 1992, the Netherlands. Alphen aan den Rijn: Samsom Publishers, pp. 11-42.

Lacity, M., \& Khan, S. A. (2016). Transaction Cost Economics on Trial Again: A Commentary on "The Role of Transaction Cost Economics in Information Technology Outsourcing Research: A Meta-Analysis of the Choice of Contract Type". Journal of Strategic Information Systems, 25, 49-56.

Lee, A. S. (2016). A Commentary: Theory Appropriation and the Growth of Knowledge. Journal of Strategic Information Systems, 25, 68-71.

Lee, W., Aggarwal, P., Shin, H., Cha, T., \& Kim, S. (2008). Markets, Hierarchies, and the Evolving Nature of Interorganizational Cooperation. In W. Lee (Ed.), E-Business Models, Services and Communications (pp. 1-21). Hershey: IGI Global.

Löwer, U. M. (2006). Interorganisational Standards - Managing Web Services Specifications for Flexible Supply Chains. Heidelberg: Physica.
Malone, T. W., \& Crowstone, K. (1994). The Interdisciplinary Study of Coordination. ACM Computing Surveys, 26(1), 87-119.

Malone, T. W., Yates, J., \& Benjamin, R. I. (1987). Electronic Markets and Electronic Hierarchies. Communications of the ACM, 30(6), 484- 497.

McAfee, A., Bettiol, M. \& Chiarvesio, M. (2007). Electronic Hierarchies and Electronic Heterarchies: Relationship-specific Assets and the Governance of Interfirm IT. Working Paper, Harvard Business School, No. 07-046.

Mintzberg, H. (1979). The Structuring of Organizations. Englewood Cliffs/NJ: Prentice Hall.

Mulherin, J. H., Netter, J. M., \& Overdahl, J. A. (1991). Prices are Property: The Organization of Financial Exchanges from a Transaction Cost Perspective. Journal of Law and Economics, 34, 591-644.

Ouchi, W. G. (1980). Markets, Bureaucracies, and Clans. Administrative Science Quarterly, 25(1), 129-141.

Parker, G. G. \&Van Alstyne, M. W. (2000). Information Complements, Substitutes, and Strategic Product Design. In Proceedings of the ACM Conference on Electronic Commerce, Minneapolis, Minnesota.

Parker, G. G., \& Alstyne, M. W. V. (2005). Two-Sided Network Effects: A Theory of Information Product Design. Management Science, 51(10), 1494-1504.

Phelps, B. (2007). Electronic Information Systems and Organizational Boundaries. Technology Analysis \& Strategic Management, 19(1), 17-29.

Pirrong, C. (1999). The Organization of Financial Exchange Markets: Theory and Evidence. Journal of Financial Markets, 2(4), 329-357.

Reimers, K. (1996). The Non-market Preconditions of Electronic Markets: Implications for Their Evolution and Applicability. European Journal of Information Systems, 5(2), 75-83.

Rochet, J. \& Tirole, J. (2001). Platform Competition in Two -Sided Markets. In Proceedings of the Joint Workshop on Industrial Organization, Toulouse, France.

Rochet, J. C., \& Tirole, J. (2002). Cooperation among Competitors: Some Economics of Payment Card Associations. The Rand Journal of Economics, 33(4), 549-570.

Rochet, J.-C., \& Tirole, J. (2006). Two-Sided Markets: A Progress Report. The Rand Journal of Economics, 37(3), 645-667.

Van de Ven, A. H. (1993). The Institutional Theory of John R. Commons: A Review and Commentary. Academy of Management Review, 18, 139-152.

VICS (2010). Linking CPFR and S\&OP: A Roadmap to Integrated Business Planning. White Paper, Voluntary Interindustry Commerce Solutions (VICS), Ver. 1.0, September 2010.

Wigand, R. T. (2011). 20 Years of Research in Electronic Markets and Networked Business: An Interview with Thomas Malone. Electronic Markets, 21(1), 5-17.

Williamson, O. E. (1975). Markets and Hierarchies - An Analysis and Antitrust Implications. New York: Free Press.

Williamson, O. E. (1987). The Economic Institutions of Capitalism Firms, Markets, Relational Contracting. London: Collier Macmillan Publishers, first published 1985.

Williamson, O. E. (1996). The Mechanisms of Governance. New York et al.: Oxford University Press.

Williamson, O. E. (2008). Outsourcing: Transaction Cost Economics and Supply Chain Management. Journal of Supply Chain Management, 44(2), 5-16.

Yuan, S.-T. (2007). The TradeCard Financial Supply Chain Solution. International Journal of Cases on Electronic Commerce, 3(1), 48-70. 